Revista Iberoamericana, Vol. LXXV, Núm. 229, Octubre-Diciembre 2009, 1077-1094

\title{
LOST IN THE MUSEUM OF NATURAL HISTORY DE PEDRO PIETRI O LA MIRADA IMPOSIBLE: "NOTES FOR FUTURE REFERENCE"1
}

\author{
POR \\ Juan Carlos Quintero Herencia \\ University of Maryland, College Park
}

Desde el título aparece levantada la experiencia que singulariza el relato: Lost in the Museum of Natural History es un texto sobre la pérdida. ${ }^{2}$ Se trata de un texto donde tanto la falta de dirección como la ruina de una preceptiva comparten el cuerpo. El cuento del escritor puertorriqueño Pedro Pietri trabaja con la perdición y desde ella traza sus efectos. La condición de lo perdido, más bien, la perdición es el pivote de un discurso del otro, sobre el otro que, en este texto, tanteará desde los sentidos del rechazo cruel ("piérdete/get lost”), el arrebato sensorial (la nota, la saturación etílica o narcótica), la desorientación de algún paseante hasta la caída de esos discursos autorizados para la formación ciudadana. El viaje aquí, por lo tanto, será, en más de un sentido, el relato de una pérdida textual. Más todavía, la lectura como actividad perdida, dilapidada, como derroche de sentidos, como la propia escritura, tomada ahora como imposible puesta en orden de lo percibido, encuentran en esta historia constantes signos equívocos, saltos y exige sus desarreglos. El relato de Pietri efectúa la pérdida sobre su textualidad.

No estaría mal insistir que perderse es no reconocer el territorio sobre el cual nos deslizamos. Perderse conlleva no encontrar referentes familiares que permitan llegar a donde, en principio, quisimos llegar. A fin de cuentas, perderse es la interrupción peligrosa de ciertos viajes que deben acabar en algún punto preciso. Parecería que sin los presupuestos de la familiaridad nos perdemos $y$, tal vez, nos asomamos al desconocimiento, o atisbamos ese conocimiento otro de un "nosotros" donde definitivamente no nos reconocemos, no nos sabemos o sencillamente no somos. Más aún, la perdición en tanto ocaso absoluto es la premonición redundante del

\footnotetext{
1 La versión preliminar de este trabajo fue leída por vez primera en el Simposio: XVI Encuentro Caribeño: Fugas y reconfiguraciones, Departamento de Literatura Comparada, Universidad de Puerto Rico, Río Piedras, 27 de marzo de 1996.

2 Manejamos la edición bilingüe, Pedro Pietri, Perdido en el Museo de Historia Natural/Lost in the Museum of Natural History. Trad. Alfredo Matilla Rivas (1986). Esta edición no enumera las páginas.
} 
vacío como horizonte. Quizás en toda pérdida se trata de avizorar la posibilidad de abandonar el "nosotros" donde hubiésemos encontrado un destino, o por lo menos asomarnos a las condiciones que sugirieron la pérdida. Quien se pierde definitivamente, desaparece. Así, la angustia pero también cierto goce pueden ser, para algunos, el soundtrack emocional de su perdición.

Si bien el cuento de Pietri es, de algún modo, un relato sobre los avatares de aquel que se desplaza, de aquel que se pierde entre familiares, este relato es asimismo un texto que rearticula un prolífico gesto en las letras occidentales. No se trata solamente del reconocidísimo enfrentamiento e intercambios del autor con sus personajes que tiene en las obras de Pirandello, Unamuno, Sartre, Beckett, Ionesco o Jean Genet momentos y variantes paradigmáticos. Estamos ante un relato que ficcionaliza el irrecusable carácter conflictivo que define, por igual, la sociabilidad de un sujeto que escribe, como la que conforma una cotidianidad signada por la masificación de la experiencia. La negatividad del espacio público es un tema recurrente en la obra literaria de Pietri. Inclusive el Lost in the Museum of Natural History, Pietri recoge los dados donde los había dejado en su extraordinario Puerto Rican Obituary (1973). ${ }^{3}$

Dead Puerto Ricans

Who never know they were Puerto Ricans

Who never took a coffee break

from the ten commandments

to KILL KILL KILL

the landlords of their cracked skulls

and communicate with their latino souls

Juan

Miguel

Milagros

\footnotetext{
3 El Puerto Rican Obituary fue pobremente editado en New York por la Monthly Review Press en 1973. Manejo la edición bilingüe de 1977 del Instituto de Cultura Puertorriqueña y me circunscribo al texto en inglés. La traducción de Matilla Rivas es por demás problemática y en ocasiones dudosa. Efraín Barradas, en una reseña temprana, se ha referido a los problemas de la traducción del Lost in the Museum of Natural History. Habría que señalar algo en torno a la desaparecida Colección de orilla a orilla que dirigiera el escritor José Luis González y que tuvo como director gráfico al artista Antonio Martorell. Se trataba de una prometedora colección bilingüe que imaginó una mayor geografía cultural isleña. Se lee en la cobertura: "De orilla a orilla, vale decir, de la Isla donde se forjó una cultura nacional puertorriqueña a la gran comunidad que en la emigración mantiene y enriquece con sus propios aportes esa tradición cultural.” La colección editaba el original y su traducción en una suerte de pequeño acordeón-pliego a color. El Lost in the Museum of Natural History fue impreso con grabados del artista José Antonio Peláez. A caballo entre una edición de bolsillo y una más bien artesano-experimental, el texto literario editado en esta colección se convertía en un pequeño objeto que debía ser manejado y manoseado con igual intensidad y cuidado.
} 


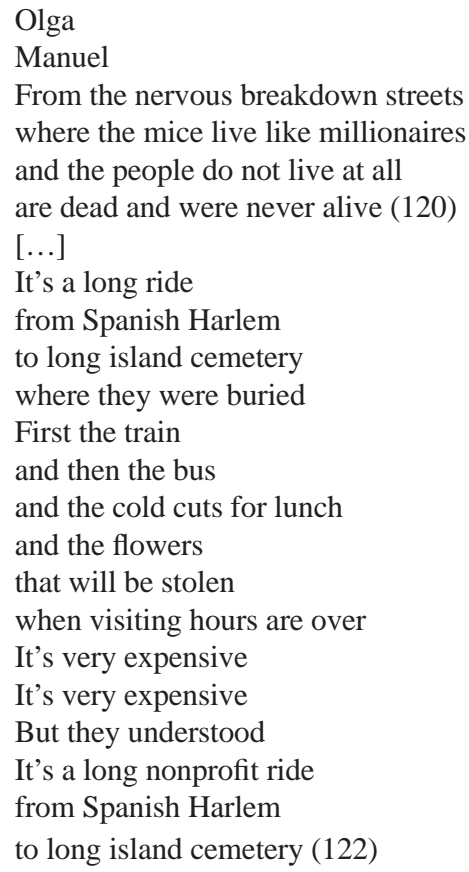

Muy temprano en el cuento ya es posible detectar la re-escritura, en prosa, de algunos pasajes del célebre poema:

Honest hard workers from neighborhoods that are hazardous to your health escaping the agony and eternal aggravation of the asphalt battlegrounds their below standards of living have confined them to. Today their bill collectors will be buried in unmarked graves in mental cementeries. [...]

For some it will be the first and last time that they will come to the beach this summer. The trip is too expensive to take more than once if your local fortune teller is having a consistent streak of unrealiable predictions. These are the ones in the cateogry of "poorer people" who will chew their bread and butter picnic lunches from the time they get to the beach until it is time to return to the vicinity where destruction is inevitable. (n. pág.)

Pietri reorientará la escenografía y el tono del Obituary, distribuirá los sentidos del viaje, dotará de “imaginación” a sus personajes e insistirá, de otro modo, en la indiferencia de los planos de la realidad o irrealidad que habitan sus personajes o por lo menos repetirá la perpetuidad de algunas condiciones violentas. La muerte encapsulada en una temporalidad que indiferencia su particularidad, sin diferendos 
entre el ayer, hoy o mañana; muerte padecida por Juan, Miguel, Milagros, Olga, Manuel en el Puerto Rican Obituary al desconocer la "geography of their complexion" (136) parece quedar atrás y ser revertida con esta "ida a la playa" recogida en el Lost in the Museum of Natural History. Por otra parte, en el Puerto Rican Obituary el consumo y la consumición son actividades problemáticas, escasas, y por lo general, política y moralmente desdichadas. En el Lost in the Museum of Natural History la consumición de alimentos y sustancias nunca cesa y deviene una poética de la confusión de las identidades y preceptivas de los personajes. Más aún en el Lost in the Museum of Natural History "los bañistas" nunca son identificados como puertorriqueños. De hecho el gentilicio aparece sólo en una ocasión para designar el ron que está tomando el autor mientras escribe: "I have a pint of Puerto Rican rum from Ponce that I am drinking from at intervals in between punctuations on my notes for future reference” (n. pág.). Este cuento de Pietri también ensaya un particular abandono, contrariado sin duda, de cierta imagen de la "comunidad" como condición y asiento para la escritura literaria de su autor.

Abro un paréntesis para la lengua. La peculiar lengua literaria de Pietri, que si bien "se escucharía mejor” en inglés, está saturada de reverberaciones significantes, inaudibles sin el español puertorriqueño. Ningún sacerdocio académico que toma el spanglish como evangelio, hasta ahora, le ha hecho justicia a la naturaleza de sus mejores proposiciones literarias. La de Pietri es una lengua perdida, no en el sentido de lengua olvidada, muerta o extinta, sino de una lengua entre-tenida, colocada entre y con-otras lenguas, habida entre emisiones múltiples. Tampoco esta situación de su lengua puede apreciarse a través de alguna "traducción" simple, certificada por algún misionerismo que decante e idealice la potencialidad híbrida del spanglish. Sin duda, los mejores textos de Pietri no están escritos en una lengua pura o castiza (si algo así existe), coherente aún en sus combinatorias o contaminaciones. Diré que lo anterior no es un gesto deliberado en el Lost in the Museum of Natural History, pero sí es decisivo para saborear las iluminaciones del Puerto Rican Obituary. Lost in the Museum of Natural History es un texto donde Pietri trabaja, de otro modo, esa lengua próxima con la que gustó de llevar a cabo sus performances públicas. La proximidad de esta lengua literaria, en particular, ha hecho de la cercanía el enigma de su lógica, de su tonalidad, el enigma de su condición discursiva, de su misterio lingüístico como pérdida de la comunicabilidad, de la habilidad misma de los personajes para comunicarse entre sí a pesar de su supuesta cercanía. El carácter entre-tenido de esta lengua no habría que reducirlo a su insistente trabajo con la oralidad sino apreciar allí el serpenteo de su camuflaje. La proximidad de esta escritura produce y tematiza una subjetividad literaria más que cristalizarla en alguna identidad o comunidad. Se trata de una condición de 
enunciación agujereada por su relación con el otro. ${ }^{4}$ El narrador de Pietri, en este texto, ha consumido, se ha embriagado (adelantemos) con la cercanía atroz de sus personajes y sólo parecen quedar los matices brumosos, yuxtapuestos, inconexos propios de esa ebriedad, de esa realidad ya incorporada.

El Lost in the Museum of Natural History podría, asimismo, colocarse dentro de una vasta serie de textos que trabajan con el lugar del autor frente a las experiencias modernas que suponen la masificación urbana y que tiene, por lo menos, en el Caribe y sus diásporas una considerable bibliografía. Me conformo aquí con situar momentáneamente el texto de Pietri junto a dos versiones caribeñas ${ }^{5}$ de esta escenografía e intentar contestaciones a la siguiente pregunta: ¿Cómo conjura o cómo produce un autor el relato de la pérdida de su autoridad escritural? La pérdida que relata Pietri en su cuento inscribe otros modos ante los gestos que frente a la masa ensayaran, por ejemplo, las crónicas neoyorquinas de José Martí o las reflexiones autoriales de Edgardo Rodríguez Juliá en algunas de sus crónicas. Mis contestaciones pendularán entre estos dos textos acercándose, tal vez, a la poética que tantea el escritor para ensamblar su relato. El texto de Pietri recogería un momento de perdición que exacerba y hasta cierto punto parodia algunos gestos tradicionales que se han asomado al reguero y la rotura modernos. Además, el relato de Pietri altera algunos lugares comunes de una tradición escrituraria latinoamericana que insistió en producir una relación estable, carente de quiebres perceptivos, entre el sujeto que narra y la masa, entre el autor y las formas de su otredad. Se trata de una tradición compleja que tiene diversos momentos en varios géneros y contextos nacionales, pero posee instancias paradigmáticas en la crónica periodística decimonónica latinoamericana, sobre todo, modernista, las notas o los diarios de viajes de ese mismo siglo y recientemente la crónica contemporánea. ${ }^{6}$

\footnotetext{
4 Más de un texto de Pietri puede servir de caja de resonancia para aquello que Derrida denomina y problematiza como "monolingüismo del otro": "Pero por esta misma razón, el monolingüismo del otro quiere decir además otra cosa, que se descubrirá poco a poco: que de todas maneras no se habla más que una lengua, y no se la posee. Nunca se habla más que una lengua, y ésta, al volver siempre al otro, es, disimétricamente, del otro, el otro la guarda. Venida del otro, permanece en el otro, vuelve al otro" (59). Sobre "las lenguas" de Puerto Rico léase, Duchesne Winter, "Puerto Rico y las lenguas de su soledad".

5 La "caribeñidad" de estos textos no habría que entenderla como la emanación esencial de algún cuerpo antropológico, lingüístico o de algún dogma nacionalista, mucho menos como parte de esa sarta de lugares comunes, que cierta multiculturalidad mercadea sin pausa. Se trata de una condición corporal situada en lo caribe, en relación con, como parte de un relato sobre lo caribe que no ontologice sus especificidades. En el sentido que propone Glissant, esta antillanía o caribeñidad es una poiesis ansiosa por salir de su "propia lengua", de errar por otra lengua o idioma, de vagar por donde pueda ensayar un pensamiento de otro modo, por donde pueda escapar de los protocolos de la mismidad. Véase Glissant.

${ }^{6}$ Ante el momento fundacional del la crónica moderna latinoamericana siempre es un comienzo el imprescindible estudio de Julio Ramos, Desencuentros de la modernidad en América Latina. En
} 
Otro deseo de éxodo bibliográfico e identitario sostiene mi fugaz "colocación” del texto del puertorriqueño Pietri entre dos autores canónicos caribeños. Se trata de un deseo por rebasar los bloqueos hermenéuticos, los protocolos compartidos por cierto latinoamericanismo, parcelas de los "Puerto Rican Studies", los "Latino Studies" o los mal llamados “Ethnic Studies”. Todos estos estudios participarían en una suerte de arena hermenéutica que gusta de proclamar la apertura o resignificación de zonas de la cultura contemporánea pero nunca se pregunta por los presupuestos autoritarios que sostienen el tinglado identitario que se desea "democratizar" o ampliar con una nueva lista de lecturas, temas o acercamientos. Con Pietri podríamos saltarnos esas vallas discursivas que, impuestas sobre algunas voces críticas, se ven condenadas a no salir de esa cantaleta apologética que se le dedica a una supuesta identidad beata, aun en su desempeños "subalternos y contestatarios". Se trata de una repetición inconsecuente acostumbrada a sustituir los opuestos de una galería de personajes del bien y el mal, donde se protagoniza el melodrama de víctimas y victimarios que ha anidado en tanto archivo cultural. Como sugiere Juan Duchesne Winter, en su glosa/conversación con Alberto Moreiras, se trataría de no insistir en esta ideologización de lo identitario como supuesta alternativa en el juego inflexible de don hegemón:

El subalterno que no puede sino repetirse en su contestación como subalterno
reiterando su compulsión de repetición como incapacidad de otredad, encarna en
su propia repetición de sí al hegemón: la continuidad del programa. Por tanto, la
perspectiva de la subalternidad sólo puede interesar en la medida en que presenta
prospectos de interrupción de la dialéctica que la constituye, es decir, en la medida
en quemejor accedaa la desindentificación radical con el juegoidentidad/diferencia
que condiciona incluso la posicionalidad subalterna. ("Fatiga de identidad” 31)

Cabe añadir que al trabajar con uno de los escritores emblemáticos de la comunidad puertorriqueña en Nueva York, quisiera advertir también esa extraña moneda de cambio literario-cultural que es "lo puertorriqueño" tanto en los campos intelectuales latinoamericanos y estadounidenses como en sus respectivas academias. ${ }^{8}$ Situar a Pietri entre el Martí y el Rodríguez Juliá cronistas es, sin duda,

el contexto mexicano la crónica contemporánea ha adquirido una relevancia indiscutible. Véase Corona y Jorgensen. Por otra parte, puede consultarse una introducción reciente sobre los temas de violencia y condición urbana latinoamericanas en Rotker y Goldman.

7 De Alberto Moreiras puede consultarse su The Exhaustion of Difference. The Politics of Latin American Cultural Studies.

8 Arcadio Díaz Quiñones ha apuntado, a su modo, hacia el “desdén” que recubre el debate en torno a la futuridad e indeterminación de "lo puertorriqueño" como sinónimo de desintegración cultural o subordinación colonial: "Salta a la vista, por ejemplo, en la carta de un francés publicada no hace mucho en el diario El País de España. En ella se afirma que Puerto Rico, en contraste con Cuba, es 
un modo perverso de reconsiderar las autofiguraciones del escritor, las ficciones de autoridad en esos textos donde la primera persona que narra coincidiría con el nombre del autor. Pero situar este texto allí no implica tampoco que los diferendos que surjan de este careo de poéticas de alguna manera se conviertan en un pretexto para clasificar o descalificar las poéticas que el texto de Pietri dejaría, quizás, a un lado. Y aunque no pueda adentrarme en esto ahora, tampoco el texto de Pietri es un caso excepcional en medio de la vasta bibliografía literaria latinoamericana contemporánea.

La ficción de autor, en muchas de las crónicas antes mencionadas, pulsa zonas de un relato familiar. Los presupuestos de la familiaridad, en más de un sentido, posibilitan la mirada de los cronistas antes aludidos. Recordemos cómo, en el orden del conglomerado, en su crónica "Coney Island”, ${ }^{9}$ el sujeto martiano decretaba su incomodidad ante esa playa dominada por las formas de una femineidad problemática, extraña, desfamiliarizante. En "Coney Island” Martí consigna “alemanas fornidas” (126), “ásperas irlandesas” (127), “mujeres barbudas” (124), prolifera allí, además, un sujeto extrañísimo para el cronista cubano: la madre solitaria. Julio Ramos ha discutido con lucidez, cómo en muchas de las crónicas martianas la ciudad no sólo es un peligroso espacio femenino, sino también un mundo donde se verifica la escisión familiar. La ciudad está llena de familias rotas y de perfiles genéricos que rebasan un ordenamiento polar:

En ese mundo de lo «singular», de lo «impar», de lo «extravagante», se rompe la pareja. Algo brilla por su ausencia: falta el padre. Al romperse la pareja se fractura la unidad mínima del sentido, el fundamento del modelo del mundo que opera en Martí; modelo de la continuidad histórica basado en la filiación. El árbol del mundo es a la vez genealógico. (184)

Cien años después, el puertorriqueño Edgardo Rodríguez Juliá en su extraordinaria crónica El entierro de Cortijo abriría un paréntesis en su mirada al entierro del plenero mayor puertorriqueño, precisamente, para insertar un relato

\footnotetext{
“un objeto nacional no identificado". En muchas partes, aun en los Estados Unidos, y en círculos de "hispanistas” profesionales, despierta más rechazo que admiración. Por supuesto, el desdén puede mezclarse con una ambigua admiración al estereotipo. En esa dirección apunta lo declarado por un integrante del grupo rock mexicano Café Tacuba en el diario Página 12 de Buenos Aires. Hablaba sobre las posibilidades que tienen los rockeros latinoamericanos de entrar al mercado norteamericano y global. [...]: ‘En Puerto Rico, de donde vienen Ricky Martin y Jennifer López, no sólo hablan inglés desde pequeños: son finalmente como un híbrido norteamericano-latino, o latino-norteamericano, que quién sabe qué, en realidad. Esas son las personas que están teniendo éxito"” (63).

9 “Coney Island” se publicó en La Pluma, (Bogotá), el 3 de diciembre de 1881. Véase Martí, Obras completas IX, 121-128.
} 
familiar que, de alguna manera, de cuenta de esa relación conflictiva, entre el deseo y la extrañeza, incluida la repulsión, que atraviesa sus preocupaciones ante "la otra cultura”. Embelesado y atropellado en medio del séquito funerario, el cronista queda absorto ante los zapatos two tones de un "doliente” próximo. Se trata de la irrupción inquietante de una imagen demasiado familiar, demasiado íntima tal vez:

Ya entrábamos a La Providencia y la catástrofe anunciada no había ocurrido cuando me asaltó una imagen perturbadora: Z93 seguía tronándome con los éxitos de Cortijo, volándole los sesos, a este exaltado y apasionadísimo Cortijo fúnebre; acentuado el silencio del conguero con rumbón que los muchachos de Lloréns traían en el pickup que seguía al féretro, vi aquellos zapatos two tone al lado de la cama, las chancletas de Chefa, también tiradas sobre la esterilla que cubre el entablado, justo al bajar los pies inquietos sobre el colchón... (Rodríguez Juliá 62)

Tras una pausa marcada en el texto con una fila de tres asteriscos, de repente nos encontramos ante una serie de instantáneas "familiares" que la imagen de los zapatos ha detonado. Un posible antepasado del autor, Don Benicio Fernández Juliá, "pico de oro coalicionista”, hace una parada en la calle Providencia:

Corría el año 1937. Palés proclamaba, en su Tun Tún de pasa y grifería, que la antillanía de la Villa Palmeras proletaria prevalecería sobre el recinto corso pequeño-burgués mallorquín del San Juan antiguo y Miramar. Pero la realidad está hecha sólo en parte de visiones. Hay que acatar también la observación, y los zapatos a dos tonos van con el traje dril a lo Lloréns de ese legislador coalicionista que baja la cuesta de La Providencia en un Packard reluciente. (62)

Estamos ahora en casa de su amante negra, Chefa, con quien Fernández Juliá tiene relaciones sexuales. Don Benicio ha comido opíparamente y al son de sus flatulencias muere en medio de un fulminante patatús. Cuando regresamos al inventario de "las tribus" que la discursividad de la "gran familia puertorriqueña" apenas logró interpelar, el cronista de El entierro de Cortijo es enfático: “Así es que los muertos invitan estas presencias; las calles y las casas son espacios donde tantos fantasmas buscan algún frágil asidero, esa precaria redención del recuerdo, o la aún más inasible estadía que sólo la imaginación concede” (66). Ésta es la manera en que una particular concepción de la imagen como nemotecnia, llamada polarmente por Rodríguez Juliá, primero visión, luego observación, es articulada como detonación de la memoria, como apertura de una sensibilidad hacia un tiempo y espacio otro. Sin embargo, esta relación con la otredad del tiempo y de sus diferencias siempre carga, en Rodríguez Juliá, un sustrato familiar, algo propio. Los fantasmas familiares se le cruzan al Rodríguez Juliá cronista a partir de la contemplación de la indumentaria de los demás, de sus estilos al llevar públicamente el cuerpo. Allí 
entonces emerge la desnudez somática, abyecta del cuerpo genealógico. El autor escribe entonces para conjurar esas mortandades familiares y para repensar a esos ausentes domésticos que alguna vez desearon "fuera de la casa", caminando por el barrio de los demás.

El entierro de Cortijo es una de esas crónicas mortuorias de Rodríguez Juliá donde su reflexión en torno a la muerte desemboca en una constante meditación sobre la identidad nacional como conflictividad, como agonía en cualquiera de sus acepciones. ${ }^{10}$ La escritura es en El entierro de Cortijo, además, un anhelante recorrido visual sobre una escenografía escatológica que simultáneamente permite observar, ligar el otro cuerpo e intentar redimir la otredad suma: la muerte de lo propio, el ocaso del antepasado verbal y literario. Con cierto paso funéreo y al decir de Julio Ramos, si: "Martí no se entrega a los flujos. Se resiste, en cambio, y reclama distancia. Diseña -en el discurso- modos de sujetar, de restaurar el poder del sujeto sobre la heterogeneidad amenazante de la ciudad” (192). Rodríguez Juliá, por su parte, se ata a lo que Rubén Ríos Ávila ha llamado el "espacio autorial” (“La invención de un autor” 38), un recinto donde la autoridad de la letra se resiste a deponer su legitimidad organizadora ante las voces y los cuerpos que paradójicamente la desconocen señalándole su diferencia. Ríos Ávila señala en otro momento sobre la escritura en Rodríguez Juliá: "Se escribe para aspirar a la pose, y el otro en el fondo existe para construir la pose del que escribe" (56). Por lo tanto, estas voluntades de distancia entre la multiplicidad del "ellos" y el "yo" que escribe son el efecto de un relato jerarquizador de espacios y sujetos que, de algún modo, se sabe mortificado por la caducidad misma de sus perspectivas. En otras palabras, ambos autores, Martí y Rodríguez Juliá, y a pesar de sus diferencias, espacializan estas experiencias ante la otredad para de algún modo anotarse ellos. Esta espacialización del lugar propio, de la propiedad de la voz es, sobre todo, la posibilidad para contemplar en la mirada de los otros el cuerpo deseante que delinea las voluntades protagónicas del autor. Sin embargo, en el Rodríguez Juliá de El entierro de Cortijo, a diferencia del Martí decimonónico, lo amenazante no es la feminización moderna de una sociabilidad necesitada de alguna simbolización familiar, viril que la ordene. En el caso del texto del puertorriqueño lo amenazante es la desfamiliarización tanto del espacio social puertorriqueño como de los poderes magisteriales de la letra para capturarlo. ${ }^{11}$ Tampoco la amenaza que consigna

10 Para una reflexión sobre la “crónicas mortuorias” de Rodríguez Juliá, véase el ensayo de Rodríguez Castro, "Memorias conjeturales: las crónicas mortuorias”.

${ }^{11}$ En la sección, "La muchedumbre” del ensayo "La histeria de la historia”, Ríos Ávila señala: "De cierto modo, El entierro de Cortijo es sobre todo el entierro de ese autor magisterial, ordenador, para quien la literatura funciona como una potencia fundadora. Ese autor se declara incompetente, invalidado, postergado, empujado por la energía de una muchedumbre que dinamita a cada paso la inteligencia de su misión” (81). 
Rodríguez Juliá es una suerte de nostalgia por un Origen imantado por las lógicas de la inmolación y el sacrificio que entregara ya el perfil definitivo a la Nación. ${ }^{12}$ Aún así, para estas miradas autofigurativas perderse de manera categórica es un innombrable, pues participan de la sospecha o el temor ante los esparcimientos de la pérdida. Temor y asomo al vértigo que surge a pesar de sí, pues se asoman a otra forma de pensar lo real, a otros modos de diseñar las nociones del espacio, del adentro, del afuera que obligarían a meditar sobre la particularidad de nuestro lugar o sobre el unitario proceder de lo nuestro aún en sus diversidades. Quien huye de su perdición ha vislumbrado en el cuerpo de lo heterogéneo, cual premonición, la crisis de su representatividad, de su autoridad, por precaria que sea.

Para Pietri, entonces, la escritura de esta pérdida es en primer plano la confusión de dos espacios: playa neoyorquina-Museo de Historia Natural. El perderse en un museo es también la historia de una y varios perdidos "en la playa”. La pérdida en el Museo es la metáfora opaca que recoge la condición social que el relato produce en la playa. Perdidos, por igual, están nuestra niña, "la madre” que al final descubrimos es la abuela, como el "lugar exacto" donde nuestro autor escribe el texto. La perdida en el Museo (instancia de cosificación de lo que alguna vez fue) es, en el texto de Pietri, una niña golpeada, hambrienta y drogada pero también es la condición de enunciación del relato donde el autor se mira a la cara. Nuestra niña deambula, además, vestida para el ritual cristiano en el que se cimenta la "salvación" de las almas. La niña por el contrario no recibe ni intercambia dones con la presencia de un Orden superior. Comulgar es también comer el cuerpo del dios hombre por vez primera y nuestra niña se muere de hambre.

La historia de violencia familiar en una playa neoyorquina durante un día de asueto es también la historia del lugar de la escritura de Pietri al interior de la Historia Natural de la ciudad que se solaza en la playa. Un niña de cinco años se ha perdido en la playa y llama a su madre. El autor, testigo de la pérdida, parecería narrar desde un momento previo a la confección del texto, pues en la playa se encuentra: "writing down notes for future reference". La anotación para referencia futura también inscribe el estado convulso, tenso, de esa escritura agitada en el trance mismo que supone el registro de simultaneidades y violencias continuas que registran el metier del autor. Esa referencialidad futura sería un momento de redacción, de lectura que permitirá saborear los matices “de lo que ha sucedido" en el instante del ahora playero cuando el narrador en su delirio escriturario apenas podía distinguir los pormenores de su propio texto. El narrador teje de esa manera la pérdida de la niña en el marco de un tapiz en el que la violencia de las superposiciones es la marca misma de su especificidad. La violencia, en este relato, es la forma de la

${ }_{12}$ Léase de Arcadio Díaz Quiñones, “José Martí (1853-1895): La guerra desde las nubes”. 
continuidad temporal que irónicamente enmarca pero tratan de romper los bañistas durante el día libre en la playa. La niña lleva un traje de primera comunión:

Everybody at the beach beach hears the the helpless child, but they are too busy eating to pay her any attention. She has been lost for a few hours and is very hungry and thirsty, walking in a daze looking for her mother who she was separate from in the process of closing and opening her eyes.

A mixed couple (man and woman) sharing a hot dog approach the little girl and ask her, "Are you really lost?"

"Yes, I cannot find my Mommy”, the little girl tells them. The mixed couple burst out laughing and walk away from her to look for something else to eat. I am almost tempted to offer the little girl my assistance in locating her missing mother, but since I am making this story up there is nothing I can do to help her, even though she is about to pass out from exhaustion. (n. pág.)

El autor al escribir bloquea cualquier gesto de ayuda hacia la niña. El autor participa de la crueldad, del carácter inhumano de la playa en la que medida que "inventa” la historia y no es parte de las soluciones al desgarre de la niña. La pérdida es la condición de estar textualmente en el relato; cuando la niña, finalmente, encuentra a su "madre", esta no la reconoce:

"Get away from me" her mother shouts as she pushes her daughter to the ground.

"Hey, bitch, what seems to be your problem? Aren't you glad to see me safe and sound?" she asks her mother, who is enjoying the fact that she had lost her daughter at the beach.

Hell no, I am not glad to see you, I told you when we left for the beach this morning that if you got lost you'd better stay lost, so get lost, I never want to see you again as long as I live.” (n. pág.)

La desfamiliarización es el espacio y el presupuesto de la realidad natural en esta playa: ahí reside su ficcionalidad, su artificialidad. En la historia de la niña, la pérdida, simultáneamente, devela la violencia que la ha constituido en familia y parecería, en la medida que perdida encuentra abrigo entre algunos extraños en la playa, asegurarle no ser violentada por la familia ni por los discursos institucionales que desean integrarla a "la buena vida".

Pero ¿¿cuáles son las condiciones de la pérdida para el autor? ¿Qué experiencias textuales construye una poética de la perdición? No son los personajes y sus identidades los únicos extraviados en este texto, entre ellos se pierde también el punto de emanación definitivo del texto. La "arena” de la playa es una plataforma fantástica donde se multiplica la inverosimilitud en tanto la simultaneidad de experiencias incompatibles nunca cesa: Temprano en el cuento se lee: 
Old teenagers and young senior citizens were having a nice time. Everywhere you looked, everybody was busy eating and talking about what they were going to eat next. People ate on the boardwalk, in the sand, asleep and awake, taking a sun tan; they ate swimming above and under water; the ate regardless of what recreational activities they indulge in.

The most eating was done at the outdoor cafeteria where I sit alone on the seat of a table with an opened umbrella on top, writing down notes for future references and eating a imaginary hero sandwich. (n. pág.)

Escribir y comer son movimientos constantes del relato. Pietri engulle mientras escribe, del mismo modo que los especimenes en la playa no paran de consumir en medio del desastre familiar de la niña. A diferencia del acto de escritura como ayuno, que leyeran Deleuze y Guattari en Kafka, Pietri hace de la concurrencia del ingerir y el escribir, el locus poético de donde emanan las dislocaciones que son su ficción. ${ }^{13}$ La negatividad constitutiva de esta dificultad digestiva es el sitio de la ficción y la política textual del cuento de Pietri. La pareja duda de la "pérdida" de la niña porque el verdadero extravío es el producido por la ingestión de las sustancias y alimentos en la playa. Es aquí que se puede apreciar la elocuencia del ron; su articulación permite el proceder delirante de la historia. La pérdida del narrador de Pietri es la inscripción del lugar de verdad, del trazo confuso, del embriagado, del contaminado por las sustancias intoxicantes y la crueldad perfecta que supone evitar cualquier gesto corrector ante el espectáculo sórdido del museo-playa. En este relato la embriaguez y la saturación son las metáforas matrices que anclan la pérdida como la experiencia que posibilita la escritura. Esta condición no le otorga al autor ninguna suerte de atalaya perceptiva, al contrario, la ebriedad compartida es inseparable de las violencia que padece la niña. La continua consumición de bebidas o alimentos acompañan las palizas a la niña y, más que el decorado acústico de ellas, parece operar como la manta con la cual el orden social en la playa aspira hacer invisibles dichos abusos. De aquí que la actividad de representación, la escritura misma sea en el cuento como un acto frágil, vulnerable, puesto a la intemperie, constantemente intervenido y atravesado por consumiciones de diverso tipo. Embriagado también yace el autor cuando la niña es recogida en la playa por una ganga de motociclistas "armed and dangerous with framed portraits of their motorcycles instead of the real thing":

13 "Rico o pobre, cualquier lenguaje implica siempre una desterritorialización de la boca, de la lengua, de los dientes. La boca, la lengua y los dientes encuentran su territorialidad primitiva en los alimentos. Al consagrarse a la articulación de los sonidos, la boca, la lengua y los dientes se desterritorializan. Hay pues una disyunción entre comer y hablar; y aún más, a pesar de las apariencias, entre comer y escribir: sin duda se puede escribir comiendo, más fácilmente que hablar comiendo; pero la escritura transforma en mayor medida las palabras en cosas que pueden rivalizar con los alimentos.” Deleuze y Guattari, Kafka. Por una literatura menor. 33. 
She gets stoned with them drinking wine and smoking dynamite grass. I have a pint of Puerto Rican rum from Ponce that I am drinking from at intervals in between punctuations on my notes for future reference. Wine is unkind to the mind. I have no emotional use for it. It instigates headaches and induces depression. Rum is articulate. (n. pág.)

La elocuencia del ron, insisto, es su capacidad para el arrebato. La bienvenida a la pérdida es un saludo al fluir de una experiencia extrema para la subjetividad: la embriaguez, la saturación. La pérdida es articulada como el ron, como éste último supone otro rigor y permite armar otros significados sobre las lógicas del desplazarse. Los personajes de este relato no paran de consumir, de devorar, de comer en cualquier dirección como de interpelar al autor. A pesar de que nuestro autor dice negarse a intervenir en el relato que simultáneamente escribe y presencia, sus personajes no se cansan de cuestionarlo y hasta llegan a romperle sus papeles. Para poder relatar en medio de tantas interferencias el narrador debe primeramente viajar y en segundo lugar provocar(se) la pérdida. El viaje, la nota, es la forma de su escritura, la pérdida es (d)el texto: "The train stops at the station where I'm supposed to get off. I purposely miss my stop to finish the story" (n. pág.). Perder la ruta a casa, no llegar a casa asegura el devenir de la escritura.

La aceptación de la pérdida como poética en Lost in the Museum of Natural History comparte con el poema Puerto Rican Obituary un enrarecimiento de la temporalidad lineal como garante de la veracidad del orden de lo real, así como también les son propias la suspensión de una concepción de la identidad atada a una territorialidad dura. Además, ambos son textos sobre zonas de muerte: el Puerto Rican Obituary consigna la entrada del cadáver al cementerio, el Lost in the Museum of Natural History despliega los fósiles y las respresentaciones estáticas de lo Natural. Ambas zonas, también, son espacios para pensar la confusión y desde la confusión; confundir y co-fundirse es un lugar clave en la poiesis de Pietri. De igual modo, la perdición no es exactamente un avatar de la soledad escrituraria como tampoco un sumergimiento absoluto en la muchedumbre. En el relato, en particular, se superponen las voces de varios narradores, aquí y allá aparece un narrador-pelotero, domina, sin duda, la narración la figura de ese "espectador” que recoge, en la playa, notas para "future reference", pero también surgen momentos en los cuales el narrador exhibe los poderes de su autoría. Ante los tormentos físicos que sufre esta niña "institucionalizada" por una sociabilidad que ha hecho del hedonismo un dogma totalizador, donde los bañistas aplauden y celebran su perdición, la escritura literaria es una constante tirada, un lanzamiento hacia esa otredad terrible.

Los personajes se confunden al igual que los espacios. La playa es confundida por la inestable madre con el Museo de Historia Natural; el espacio donde creímos 
que la niña se había perdido y había sido atacada por su madre se revela al final como el Museo de Historia Natural; en este mismo momento descubrimos que quien la llevó a la playa no ha sido la madre sino la abuela. En el desenlace del cuento, los padres regresan del cine y le preguntan a la abuela cómo pasó el día con la niña: "Everything went just fine. I took her to the Museum of Natural History and she enjoyed it very much” (n. pág.). La arena es la metáfora temporal que permite confundir playa con Museo; cómo olvidar esas "escenas naturales" comunes en esos museos donde las especies yacen colocadas sobre la arena del tiempo. En el saber que la Historia Natural despliega en sus panoramas, como nos ha señalado Michel Foucault, se articula una voluntad de representación que aspira a desatar la confusión constitutiva de la simultaneidad de lo real:

La historia natural encuentra su lugar en esta distancia, ahora abierta, entre las cosas y las palabras - distancia silenciosa, carente de toda sedimentación verbal y, sin embargo, articulada según los elementos de la representación, justo aquellos que podrán ser nombrados con pleno derecho. Las cosas llegan hasta las riberas del discurso porque aparecen en el hueco de la representación. [...]

Así dispuesta y entendida, la historia natural tiene como condición de posibilidad la pertenencia común de las cosas y del lenguaje a la representación; pero no existe como tarea sino en la medida en que las cosas y el lenguaje se encuentran separados. Así, pues, deberá reducir esta distancia para llevar al lenguaje lo más cerca posible de la mirada, y a las cosas miradas lo más cerca posible de las palabras. ${ }^{14}$

La escritura de Pietri metaforiza, a la vez que parodia, la posibilidad de una mirada esclarecedora sobre la realidad o lo textual. La disonancia y las interferencias de lo inverosímil son lo que lleva a cabo su escritura en tanto pérdida de la voluntad de clasificación del discurso de la historia natural. El afán, casi miope de la historia natural, de acercar la mirada a la cosa mirada es ocupado por la poética embriagante de Pietri y así desarticula la pretensión de fijeza identitaria que firma la voluntad de representación sobre "el orden natural” extendida sobre la arena de la playamuseo. Lo que observa Pietri no se le ofrece, no emerge como un vacío que su representación literaria desea clasificar o logra ordenar. Si el discurso de la historia natural produce un Orden al fijar el cuadro donde colocar el espécimen, la pérdida de fronteras entre el afuera y el adentro, entre autor y personaje, entre el yo y el otro es lo que posibilita, en el texto de Pietri, una salida, tal vez, temporera de ese orden representacional, familiar que ya nos ha ocupado y organizado sobre la arena de la Historia. Las interferencias espaciales y discursivas en el texto de Pietri desgreñan esa voluntad de representación natural, en tanto lo Natural nunca se le ofrece como

\footnotetext{
${ }^{14}$ Michel Foucault, “Capítulo Cinco. Clasificar.” 130, 132-133 respectivamente.
} 
una zona clara, abierta donde los seres despojados de algún tipo de singularidad sólo están allí colocados unos al lado de los otros. En la arena citadina de Pietri el ordenamiento de los bañistas-criaturas, su proximidad cruel en la playa es la forma misma de la violencia que define el intercambio social de la ciudad. El cuento de Pietri se niega a anudar, en una larga cadena causal, las cosas con su mirada y luego su discurso, ya que el autor no asume el lugar de una racionalidad recopiladora y, por el contrario, cede ante la persistencia sobreabundante de la simultaneidad que es como el movimiento tantálico de la niña en el metro al final del cuento.

Relato sobre la complejidad temible de los estereotipos, la "imposibilidad" de su mirada le viene de la falta de distancia frente a tales estereotipos. La realidad del margen (cultural y social) de esos personajes que en la playa-museo intentan escapar de su rutina de producción, es la cuadrícula rota para una historia deliberadamente confundida en cuanto a sus nociones de tiempo y espacio; este es un relato en vías de construcción por un observador "descalificado" que no puede mantenerse en la zona del observador inconmovible. El lugar del observador de paso, que en medio de las grandes ciudades disecta y construye un imaginario sobre la otredad, no le sirve al narrador de Pietri como una instancia de consolidación para su autoridad letrada. Los estereotipos como centros de fundición ficcional se le superponen a su propia escritura y apenas ésta los desdice. Estamos ante una mirada que ha problematizado las escrituras que aparentemente han reflejado la realidad de la ciudad cargada de inmigrantes y masificada en todos sus espacios. Las líneas, las familias rotas, la multiplicidad festiva de violencias y risas en el vocerío urbano, importunan la serenidad descriptiva, y aún las diversas experimentaciones que mucha narrativa consciente de sí misma ha reproducido ante el tópico. La violencia, el juego sádico, la risa cruel levantan esta mirada y cancelan la dicotomía interior/exterior que ha legitimado una escritura sobre los "hábitos y costumbres" del ocupante moderno de la ciudad. El reconocimiento de esa parcialidad óptica arma y desarma el relato, ya que en el mismo tanteo de esa multiplicidad de fragmentos y violencias que la playa pone en circulación, el narrador no hace sino aludir a un despliegue de trazos y pedazos de verdad frente a las cuales la "imparcialidad” sucumbe.

La relación del narrador-autor con la niña resume la condición escrituraria del texto. La mayoría de las escenas de escritura en este cuento siempre cuentan con la intervención e interrupción de una figura femenina que por igual observa, increpa o desestabiliza al autor. La niña, en específico deviene una suerte de creación que el autor protege, abandona, mata, revive y finalmente se convierte en el hueco negativo que sostiene la escritura del cuento:

The girls begs me to stop being so negative with my imagination and write about the bright side of life. I pay her no attention because I am totally broke. This story has to be griten regardless of whose feeelings get hurt. This is the way I make my living. If I am unrealiable to my fantasies the rent will not get paid. (n. pág.) 
Se escribe para hacerle justicia a las fantasías que permiten pagar la renta. Dichas fantasías además suponen la mirada de un demiurgo cruel y jodedor que en los márgenes de la playa se niega a la filantropía o el bienestar social. La marginalidad de la experiencia aquí narrada es, por lo tanto, la devaluación de la autoridad del narrador como agente externo al relato, ya que esa exterioridad narrativa se resiste en el texto de Pietri a convertirse en un modelo de organización autoritario y autorizante ajeno a las contaminaciones. El final del cuento, otra vez en pleno viaje, cierra con una escena que ironiza, hasta la burla, la precaria autoridad de nuestro autor que ahora se ve del otro lado de una fantasía que tampoco domina y que de algún modo responde al tejido de otra brega familiar en la ciudad. El autor finalmente recibe una dosis de su propia poética errante y trucosa:

What's wrong with Mommy's little baby? The younger lady asks with a frightened expressions on her face.

"I had a dream that a man dressed in black was writing a strange story about me."

When the train stops again I have all intentions of getting off, but when I try to move nothing happens, my body is motionless, I am unable to get up. The little girl I was writing about enters the train to distribute gypsy business cards. When she comes to where I am hopelessly seated she hands me one of the cards she is distributing, and quickly draws her hand back when I reach out for it, and proceeds to the next passenger coming home from the beach. (n. pág.)

Finalmente, saberse por igual mirado y espectador en el Lost in the Museum of Natural History, es saberse abocado a un modo representación atravesado, presuroso y atragantado; es reconocer que entramos al territorio de las imprecaciones, a la arena del ruido. A este autor los personajes le exigen que se "quite la ropa” y se "meta a la playa como el resto de la gente":

\footnotetext{
"Why don’t you take off your clothes and go swimming like everybody else who came to the beach."

I had all intentions of doing that, but since nobody make a pass at me when I got here, I changed my mind about being mediocre and started writing down notes for future reference. I am not anti-social, I am anti-preliminaries. I want to swallow my food first and then chew it. (n. pág.)
}

La narración sustituye, entonces, la ausencia del ligue, del pase; Pietri narra ya que no ha sido deseado. Pietro narra para alejarse de la mediocridad de aquellos que no reconocen la historia de deseos que organiza sus viajes, el sentido de lo que denominan "Realidad" y su teoría de la representación en sociedad. Su escritura no pertenece al orden de lo Natural, altera las causalidades, los preliminares que 
nos alejan del azote del instante. Exacerbada como un ataque de hambre tras la ebriedad, esta escritura se traga la comida primero y luego la mastica.

\section{BiBLIOGRAFÍA}

Agamben, Giorgio. The Comming Community. Michael Hardt, trad. Minneapolis \& London: U of Minnesota P, 1993.

Barradas, Efraín. "Pedro Pietri, narrador”. Revista Chicano-Riqueña 9/4 (1981): 66-70.

Corona, Ignacio y Beth Ellen Jorgensen, eds. The Contemporary Mexican Chronicle: Theoretical Perspectives on the Liminal Genre. Albany: SUNY P, 2002.

Deleuze, Gilles y Félix Guattari, Kafka. Por una literatura menor. [1975] Versión de Jorge Aguilar Mora. México: Era, 1983.

Derrida, Jacques. El monolingüismo del otro. Horacio Pons, trad. Buenos Aires: Manantial, 1997.

Díaz Quiñones, Arcadio. “De cómo y cuándo bregar”. El arte de bregar. Ensayos. San Juan: Ediciones Callejón, 2000. 19-87.

“Capítulo 3. José Martí (1853-1895): La guerra desde las nubes”. Sobre los principios. Los intelectuales caribeños y la tradición. Bernal, Provincia de Buenos Aires: Universidad Nacional de Quilmas Editorial, 2006. 255-287.

Duchesne Winter, Juan. “Fatiga de identidad”. Fugas incomunistas. Ensayos. San Juan: Ediciones Vértigo, 2005, 17-36.

"Puerto Rico y las lenguas de su soledad". Ciudadano insano.Ensayosbestiales sobre cultura y literatura. San Juan: Ediciones Callejón, 2001, 39-48.

Foucault, Michel. "Capítulo Cinco. Clasificar". Las palabras y las cosas. Una arqueología de las ciencias humanas. [1966] Elsa Cecilia Frost, trad. México: Siglo XXI, 1984.

Glissant, Édouard. Poétique de la Relation. París: Gallimard, 1990.

Martí, José. "Coney Island”. Obras completas, Vol. IX. La Habana: Editorial Nacional de Cuba, 1963-1965. 121-128.

Moreiras, Alberto. The Exhaustion of Difference. The Politics of Latin American Cultural Studies. Durham \& London: Duke UP, 2001.

Pietri, Pedro. Perdido en el Museo de Historia Natural/Lost in the Museum of Natural History. Alfredo Matilla Rivas, trad. Diseño y grabados. José Antonio Peláez. Colección de orilla a orilla. Río Piedras: Ediciones Huracán, [1981]. Páginas sin numerar. Obituario Puertorriqueño. Trad. y prólogo de Alfredo Matilla Rivas. San Juan, Puerto Rico: Instituto de Cultura Puertorriqueña, 1977. 
Ramos, Julio. Desencuentros de la modernidad en América Latina: Literatura y política en el siglo XIX, México: Fondo de Cultura Económica, 1989.

Ríos Ávila, Rubén. “La invención de un autor: escritura y poder”. Las tribulaciones de Juliá. Ed. y comp. Juan Duchesne Winter. San Juan: Instituto de Cultura Puertorriqueña, 1992. 33-62.

“I. La histeria de la historia”. La raza cómica. Del sujeto en Puerto Rico. San Juan: Ediciones Callejón, 2002. 15-115.

Rodríguez Castro, María Elena. "Memorias conjeturales: las crónicas mortuorias". Las tribulaciones de Juliá. Ed. y comp. Juan Duchesne Winter. San Juan: Instituto de Cultura Puertorriqueña, 1992. 65-92.

Rodríguez Juliá, Edgardo. El entierro de Cortijo. [1983] Río Piedras: Ediciones Huracán, 1988.

Rotker, Susana y Catherine Goldman eds. Citizens of Fear: Urban Violence in Latin America. New Brunswick: Rutgers UP, 2002. 